MODELING, IDENTIFICATION AND CONTROL, 2003, VOL. 24, NO. 1, 37-48

doi:10.4173/mic.2003.1.4

\title{
Storfjorden (Svalbard): Modeling of the Polynya Development and the Sea Ice Ridging Process ${ }^{\S}$
}

\author{
DENIS ZYRYANOV*, JÖRG HAARPAINTNER† and \\ REINERT KORSNES:
}

\begin{abstract}
Keywords: Plasticity, sea ice, numerical modeling and geomechanics
Remote sensing ohservations of Storfjorden ice cover described the persistence and evolution of latent heat polynyas during winter 1997/1998. The induced important ice production was quantitatively estimated by simple modeling of the sea ice dynamics and growth. In the present work we used mathematical modeling to qualitatively simulate the polynya open and developing. First, we estimate the values of internal stresses appeared in Storfjorden ice sheet due to the wind stress and used them in the model calibration algorithm. Then, we model the polynya open and developing in simple quasi-static approach. The sea ice ridging process is modeled last and the maximum of ice ridges height is estimated. The results of the simulations are compared to satellite observations from ERS-2. They show that the equilibrium stages of the model developing coincide in common with insitu data of satellite observations. From another side, the estimations show that the ice ridge keel can achieve height up to $8 \mathrm{~m}$ along the eastern shore of Spitsbergen.
\end{abstract}

\section{Introduction}

The investigated area named Storfjorden is situated in the Southeast of the Svalbard Archipelago between Spitsbergen, Barentsøya and Edgeøya (Figure 1). Storfjorden is known as Big Fjord; however, the existence of northeastern sounds makes this area unclosed. ERS-2 synthetic aperture radar (SAR) satellite observations demonstrated the persistence of latent heat polynyas in this region. Haarpaintner (1999) described the evolution of a flaw polynya (between fast and pack ice) during the winter 1997/1998 in Storfjorden. Opening under northerly winds, the Storfjorden Polynya reached a size of up to $6000 \mathrm{~km}^{2}$. According to simple ice drift and ice production models the polynya covered on average a sixth of the area $10000 \mathrm{~km}^{2}$ and was responsible for approximately two thirds of the total ice production of about $40 \mathrm{~km}^{3}$ (Haarpaintner et al., 2001).

Wind stress was stated as the main reason for the existence of the polynya, but water currents and especially strong tidal currents through the two sounds, Heleysundet and Freemansundet, in the Northeast of the fjord, may play an important role in the definition of the polynya boundaries.

Since larger heat fluxes take place in polynya and leads than in the Arctic pack ice, it is important to know under which circumstances they develop. Sensible heat

* Norwegian Polar Institute, Polar Environmental Centre N-9296 Tromsø, Norway. Email. Denis.Zyryanov@npolar.no; Tel: +47/77 7505 43; Fax: +47/77 750501

†National Ice Center, Suitland MD, USA. Email: jhaarpaintner@natice.noaa.gov; Tel: +1 (301) 457 5303; Fax: + 1 (301) 4575300

\$Norwegian Defence Research Establishment (FFI), Division of electronics, Postbox 25, NO-2027, Kjeller, Norway. Email: reinert.korsnes@ffi.no

${ }^{\S}$ An early version of this article was presented at Nordic Matlab Conference 2001, October 2001, Oslo, Norway. 


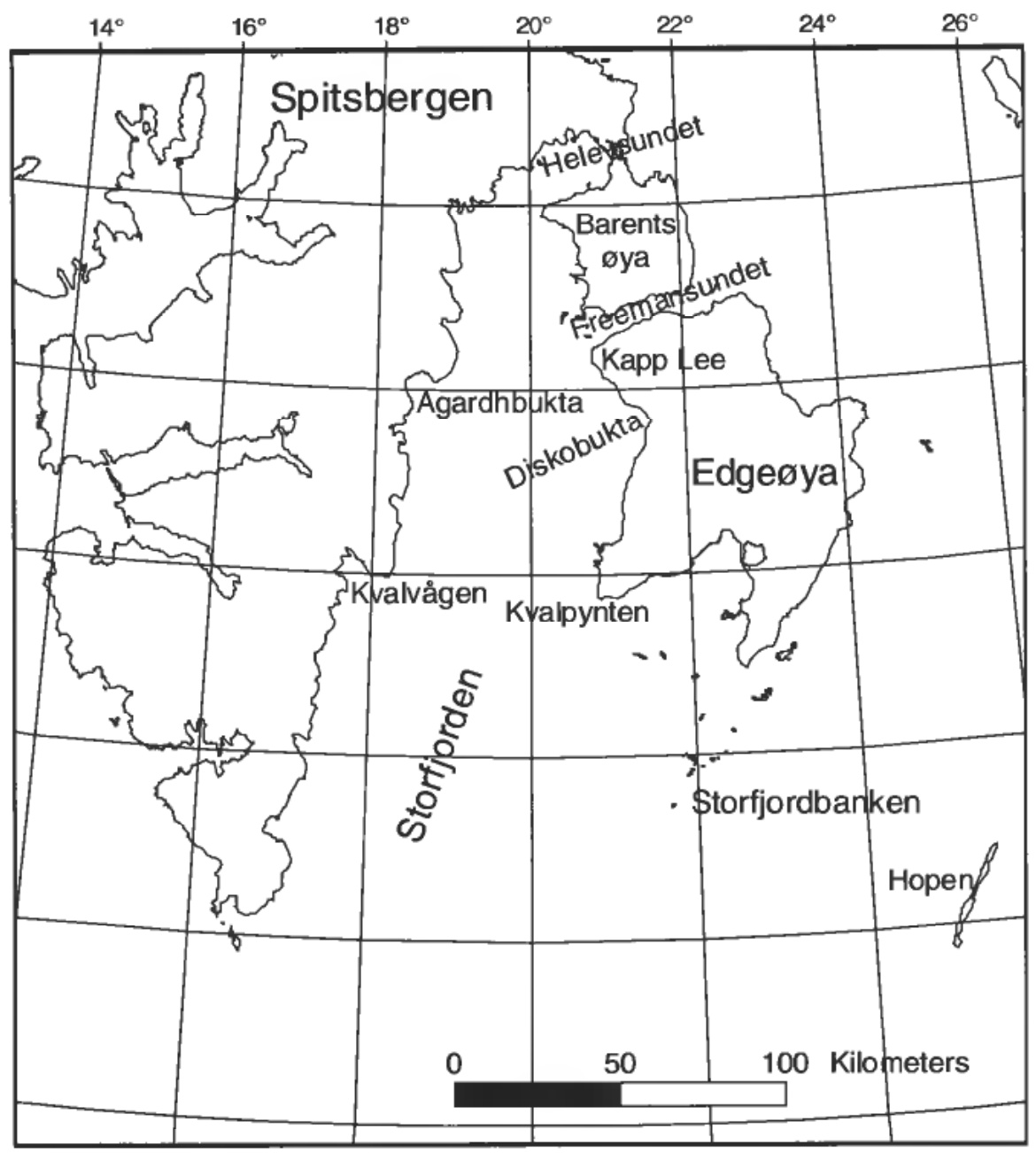

Figure 1. Storfjorden is located in the Southeast of the Svalbard Archipelago between Spitsbergen, Barentsøya and Edgeøya.

polynyas develop when oceanic heat melts the ice cover above or prevents its formation. Latent heat polynyas open mechanically under wind stress or ocean currents that transport the ice cover away and when the import of ice is blocked by land, fast ice or grounded ice on shallow shelves. Important ice production takes place and under constant atmospheric conditions, the polynya will reach an equilibrium size when ice export is balanced by ice production (Pease, 1987). However, their empiric approach cannot determine the exact conditions under which the polynya is developed. The natural observations in Storfjorden show a significant ice ridge formation in areas covered by fast ice. The estimation of the possible ice ridge heights is the aim of this work as well as the modeling of Storfjorden polynya open and developing.

In this study, we used a two-step modeling approach. First, we characterize the ice cover as a plastic-elastic two-dimensional media using the finite element theory (Section 2). This theory has widely been used to describe the deformation and failure of metals, rocks, and concrete (Nacar et al., 1989), and showed to be also applic- 
able for describing the deformation and failure of ice (Schwarz and Weeks, 1977; Marchenko, 2001). The calculations of internal stress in two-dimensional media cover the investigated area were made in a framework of a quasi-static approximation by means of MATLAB scripts. The modeling ice cover is subjected to wind drag force measured in Hopen meteorological station in 1997/1998. The first step gives quantitative assessments of wind stress and ice thickness, which are necessary for the start of ice destruction.

Secondly, (section 3) we use mathematical modeling to simulate the polynya opening and development. Our geomechanical model is based on the Particle Flow Code (PFC2d) that is widely being used in mining, environment, contaminant studies, petroleum industry etc.

Section 4 is devoted to the sea ice ridging process simulation based on a simple two-dimensional model used by e.g. Hopkins et al. (1991), where the maximum height of the ice ridges is found from the equation for the hydrostatic balance.

In Section 5, we compare the simulation results with the satellite observations (Haarpaintner, 1999) to relate how the polynya forms explaining its final geometry.

\section{Study of the stress concentration areas}

The Storfjorden area is firstly considered as a two-dimensional plastic-elastic media and analyzed by simple finite element theory to reveal the stress concentration areas. The investigation area is shown by the rectangular on Figure 2.

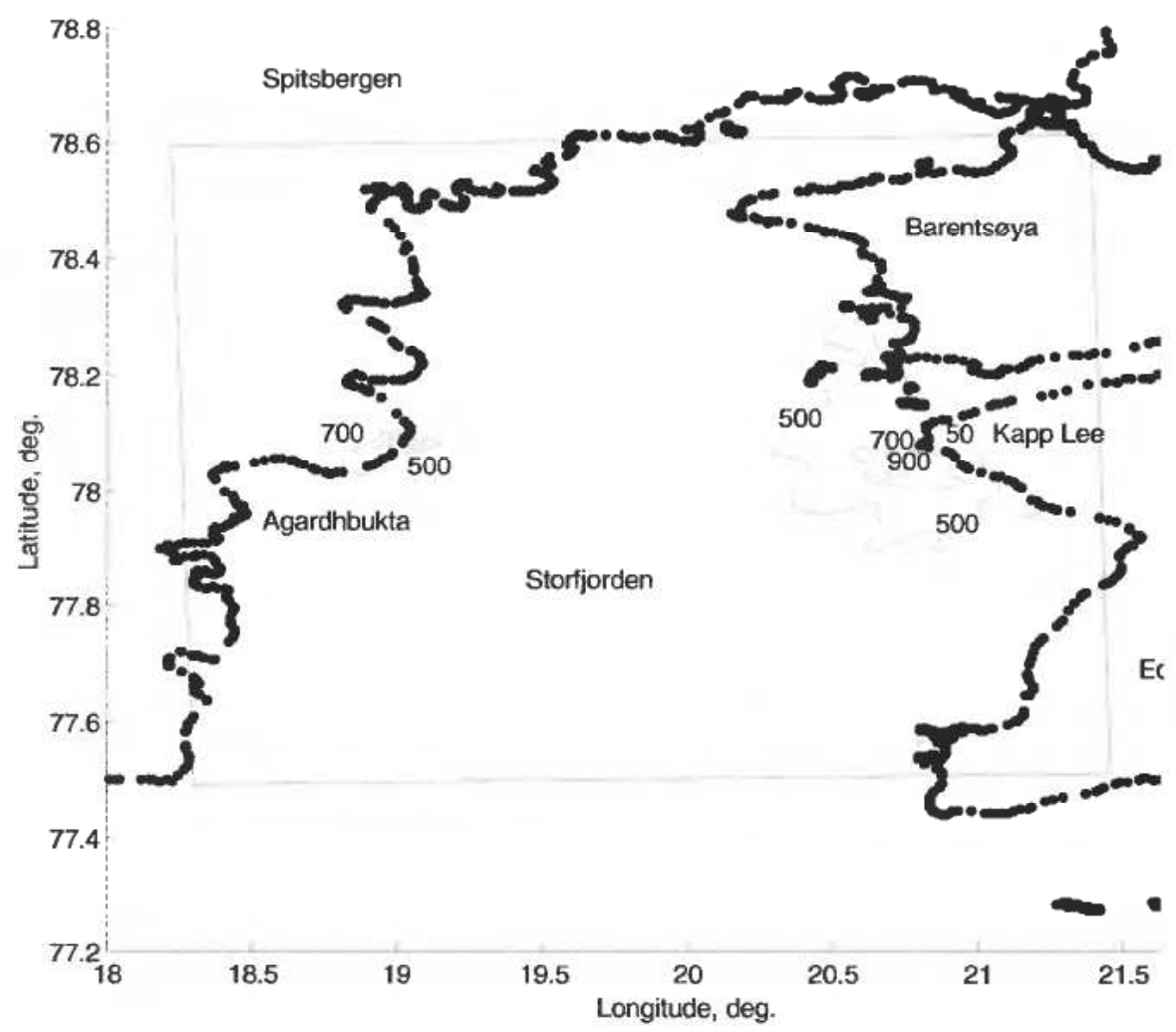

Figure 2. The tensile stress distribution in Storfjorden. The study area is shown by the rectangular. The wind stress (av. speed of $5.7 \mathrm{~ms}^{-1}$, azimuth $=40^{\circ}$ ) defines the maximum stress Ca. $1.5 \times 10^{3} \mathrm{~N} \cdot \mathrm{II}^{-2}$ IICaI Kapp Lee. 
In-situ observations show that the brine volume, ice thickness and porous percentage can vary significantly inside the investigated area, leading to the variation of the tensile/shear strength and ice plastic-elastic properties from one place to another (Bjork, 1992). There are no suitable measured data of the mentioned physical parameters in Storfjorden. Anyway such data would probably vary significantly from year to year and depend on the history of atmospheric conditions, heat fluxes etc.

Therefore, it seems to be logical to approximate the variations of sea-ice properties by means of some stochastic function (Thorndike, 2000). The function prescribes randomly distributed physical properties from a predefined range for every element in our research with aid of finite element theory.

We will assume that the ice stiffness can uniformly shift from $\sim 5 \times 10^{9} \mathrm{Nm}^{-2}$ to $\sim 9 \times 10^{9} \mathrm{Nm}^{-2}$. (Minimum value of $\sim 5 \times 10^{9} \mathrm{Nm}^{-2}$ corresponds to the sea ice with salinity of $\sim 9 \%$ under the temperature of $-7^{\circ} \mathrm{C}$, whereas the maximum value represents the fresh ice at a temperature of $-3^{\circ} \mathrm{C}$.) The Poisson's ratio $v$, i.e. the ratio between the strains in two directions perpendicular to each other in simple tension, is constant with a value of 1/3 (Mellor, 1983; Schwarz and Weeks, 1977).

To formulate the task boundary conditions, we suppose that the displacements of the finite element nodes located closest to the shoreline of Storfjorden are negligible. This means that the ice cover near the shore is stable, corresponding to coastal fast ice. The ice cover edge neighboring with open water along the line Kvalvågen-Kvalpynten (rectangular bottom on the Figure 2) is stress free. The applied drag force $\tau$ is defined by wind stress and can be calculated by:

$$
\tau=C_{D} \cdot \rho_{x} \cdot u^{2}
$$

where $\rho_{x}$ is the air density, $C_{D}$ is the surface drag coefficient, and $u$ represents the wind velocity. The air drag coefficient measured in the Arctic basin ranges from $1 \times 10^{-3}$ to $3 \times 10^{-3}$ (Banke and Smith, 1973; Overland, 1985, 1994). Langleben (1972) studied in details the dependency of the air drag coefficient upon various wind profiles. It was demonstrated that the measured drag coefficient significantly depends upon the surface roughness of the ice floes.

As input data we use the wind speed data obtained at the meteorological station on Hopen Island four times a day. The data show an average wind speed of $5.7 \mathrm{~ms}^{-1}$ from 1 August 1997 to 31 July 1998, with gusts of $20.6 \mathrm{~ms}^{-1}$ (31.10.97 1:00). Figure 3 shows the wind rose in 1997/98. As one can see the dominant wind direction is from $N E$.

As usual, the yield function:

$$
\kappa=f\left(\sigma_{i j}\right) \leqslant 0
$$

is applied to describe the material failure, where $\kappa$ is determined by some algebraic combination of stress tensor components $\sigma_{i j}$. If $f\left(\sigma_{i j}\right)<0$ the stress state is said to be elastic, or the material is at yield when $f\left(\sigma_{i j}\right)=0$.

In one case, the function (2.2) can represent the von Mises or Tresca yield criterion that assumes that yielding occurs when the maximum shear stress $\tau_{\max }=\left(\sigma_{1}-\sigma_{3}\right) / 2$ reaches some critical value. $\left(\sigma_{i}, i=1,3\right.$ denote the principal stresses.) Or, the relationship (2.2) can represent the Coloumb-Navier-Mohr yield criterion, parabolic Mohr envelope, etc.

In our study, we will concentrate on simple tensile strength (Crocker et al., 1989) and consider the only tension stress distribution inside the investigated area.

Finally, Figure 2 shows the distribution of the maximum tensile stress in the 


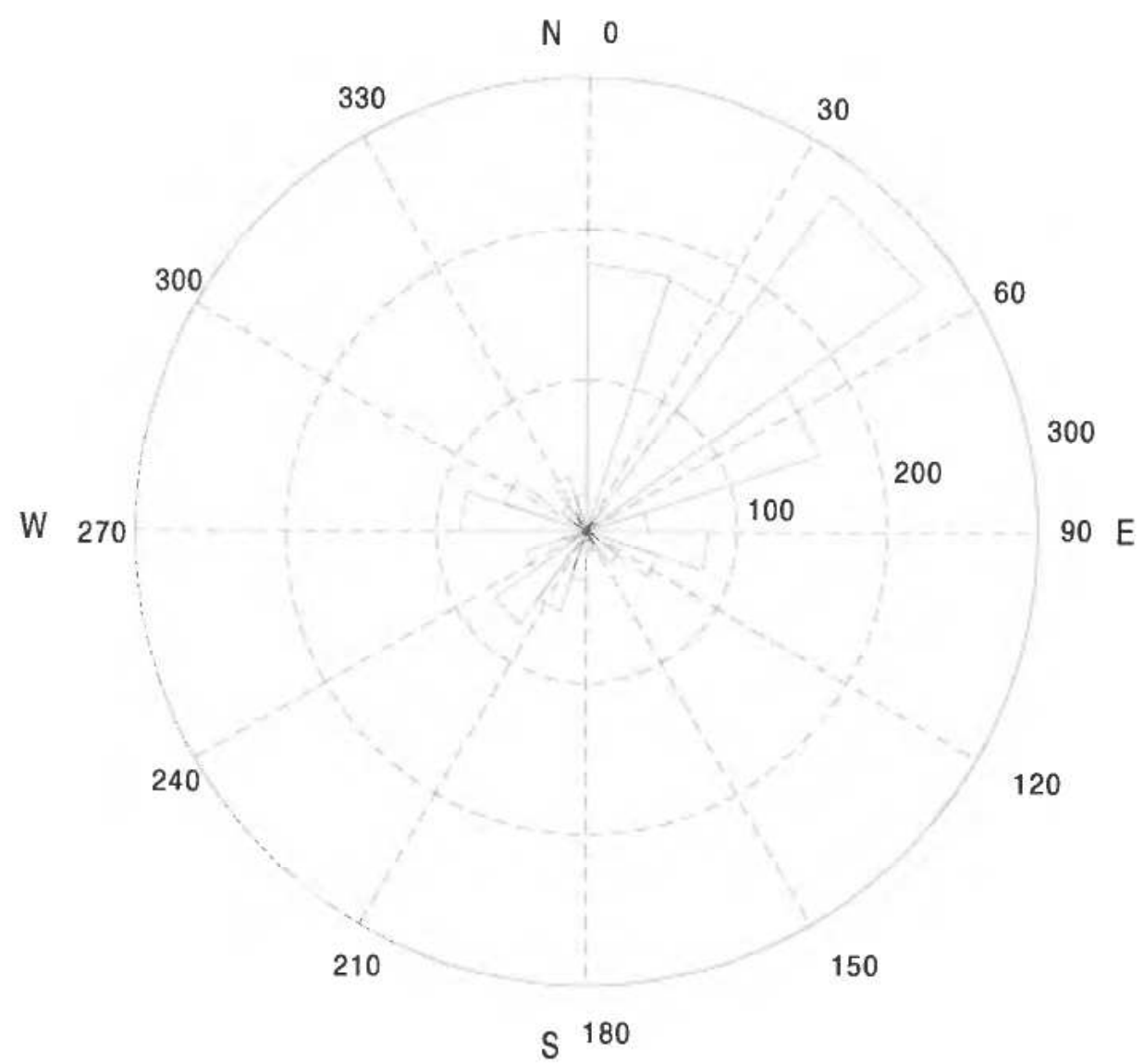

Figure 3. Wind rose in 1997/98. The dominant wind direction is from NE. Digits 100, 200, 300 indicate number of observations belonged to considered sector.

modeled ice cover made by MATLAB scripts. The simulation was executed with the following parameter values:

Table 1. Initial parameters for the stress concentration study

\begin{tabular}{ll}
\hline Parameter & Value \\
\hline Young module, E: (Uniformly distributed) & $(5-9) \times 10^{9} \mathrm{~N} / \mathrm{m}^{2}$ \\
$v$ (Poisson ratio) & $1 / 3$ \\
$\rho_{x}$ (air density) & $1.3 \mathrm{~kg} / \mathrm{m}^{3}$ \\
$C_{D}$ (drag coefficient) & $3.35 \times 10^{-3}$ \\
azimuth_ $\vec{u}$ (wind direction) & $40^{\circ}$ (dominant) \\
$|\vec{u}|$, (Average wind in 1997/1998) & $5.7 \mathrm{~ms}^{-1}$
\end{tabular}

The modeling results reveal the magnitude of tensile stress ca. $1.5 \times 10^{3} \mathrm{~N} \cdot \mathrm{m}^{-2}$ in areas where the shoreline has steep bends near Agardhbukta and Kapp Lee. 


\section{Modeling of the sea ice break up: quasi-static approach}

\subsection{Calculation instruments}

For sea ice break up simulation we have chosen the ITASCA Code (namely the PFC2d Code). The Code deals with round particles - disks, which are bonded together to simulate rigid bodies and continuum media. In the beginning of the modeling process such particles-disks uniformly fill out all free space in the investigated area (Figure 4(a), shown by rectangular). This area coincides with the area of stress exploration analyzed in the previous section. To avoid initial abnormalities in our model, we turn our attention to the case, when all disks in the numerical simulation are homogeneous - they have the equal mechanical properties and unit thickness. Originally the disks are connected (glued) to each other by means of some medium, having the same mechanical properties with the disks. Then, the external load caused by
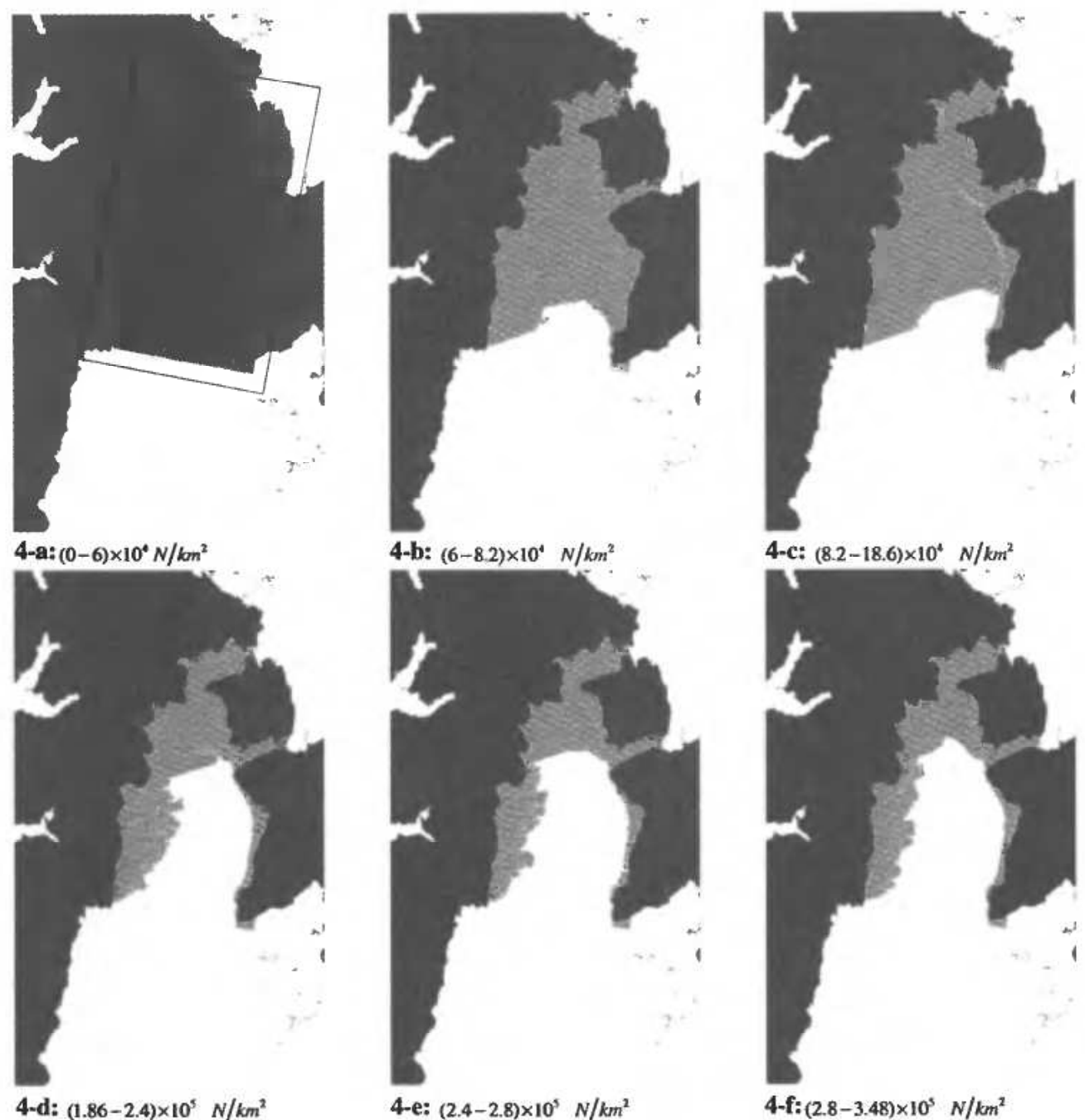

4-d: $(1.86-2.4) \times 10^{5} \mathrm{~N} / \mathrm{km}^{2}$

4-e: $(2.4-2.8) \times 10^{5} \mathrm{~N} / \mathrm{km}^{2}$

4-f: $(2.8-3.48) \times 10^{5} \mathrm{~N} / \mathrm{km}^{2}$

Figure 4. The simulation results of the Storfjorden polynya development. Every figure corresponds to the range of wind stress joined with the wind speed by formula (2.1). If differences between any two states were negligible they were merged. 
wind drag force is applied. If normal or shear stresses exceed its corresponding bond strength, the bond breaks. It leads to a break-up in the ice field and causes the ice drift. Nevertheless, after separation some pieces can be joined again if they will touch each other in a process of simulation. From physical point of view, such behavior can be stated as 'freezing' of broken particles. It must be noted that the real ice sheets exhibit many of the complex behaviors of actual brittle solids, which cannot be directly explained in terms of existing underlying theories, especially continuum theories. Since there is no explicit relationship between micro and macro physical parameters we fulfilled several series of simulations with various disk properties. Thus, the ice stiffness of separate floes cannot be directly treated as Young module of ice in large-scale simulations. The Poisson's ratio is not explicitly used in the Code. It is a function of ice particle package and ratio between normal to shear stiffnesses.

\subsection{Quasi-static loading}

Originally there is no drag wind force and the system is in static equilibrium (Figure 4(a)). Then, the drag force increases slowly and uniformly in accordance with dominant wind direction from $N E$. At every calculation load-increasing step the equilibrium stage is achieved. The static equilibrium stage is defined by absence (in the Code - if the ratio of maximum unbalanced forces among all particles to the maximum of average contact forces is less then $\varepsilon=0.01$ ) of resulting forces impacted on every disk. In that way, there is no explicit time-dependence and the system developing can be interpreted as a quasi-static process.

The ice pieces can drift away in a process of simulation; in that case they are simply deleted. Since there is a small island-reef named Storfloskjeret in the top of Storfjorden between Kvalvågen Bay and Kvalpynten Cape, some separate ice pieces can be blocked there. The simulation is stopped when the remaining area occupied by the ice floes becomes less than $20 \%$ of original extent. Figures 4 (b)-(f) show the sequential stages of the modeling ice cover destruction in Storfjorden. The parameters, which were used in the experiment with the round ice floes, are as follows:

Table 2. Initial parameters value for quasi-static model

\begin{tabular}{ll}
\hline Parameter & Value \\
\hline Floe radius: & $500 \mathrm{~m}$ \\
\# of disks in the system: & 7646 \\
Disk stiffness, $k_{n s}:$ & $5 \times 10^{9} \mathrm{~N} / \mathrm{m}^{2}$ \\
Normal/shear strength, $\sigma_{n s}:$ & $1 \times 10^{8} \mathrm{~N} / \mathrm{m}^{2}$ \\
\hline
\end{tabular}

Since there is no applicable data of ice thickness distribution in Storfjorden shortly before the polynya opening due to northeasterly winds, we use in our code the quantitative assessments from section 2 to associate the real wind stress and the simulation of ice cover destruction. As one could see the average wind speed $\sim 5.7 \mathrm{~ms}^{-1}$ during the measure time in 1997/98 leads to the tensile stress in ice field covered Storfjorden with a value of $\sim 1.5 \times 10^{3} \mathrm{~N} \cdot \mathrm{m}^{-2}$. In our model we link the beginning of failure of ice cover (Figure 4(b)) with the average wind stress magnitude. This is a core of applied calibration algorithm. The calibration is needed since some physical parameters (i.e. ice thickness, concentration of melt ponds etc.) of the real ice cover in Storfjorden have being remained unknown. 

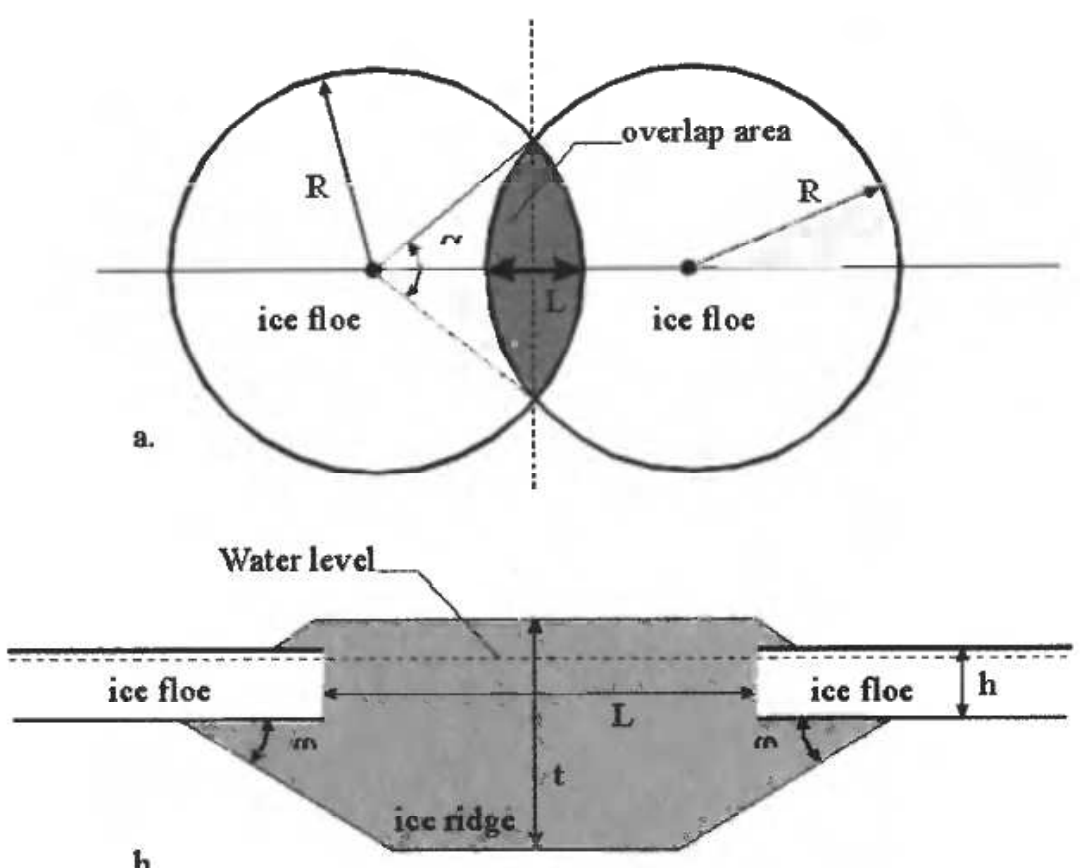

b.

Figure 5. (a) an overlap of two ice floes, (b) an idcalized ridge geometry: $h$ is the ice floe thickness, $L$-length of the overlap area, $t$ represents the high of the ice ridge, $\varphi$-keel edge angle mostly equaled to $30^{\circ}$.

Every static equilibrium stage conforms to the range of wind stress (wind speed and stress are directly related by equation (2.1)) shown below each subfigure 4 . To save a space, if differences between two sequential load increase equilibrium states were negligible, they were merged.

\section{Numerical simulation of the sea ice ridging process in Storfjorden}

The ice ridges are produced by the deformations caused by wind drag force and water currents and they are characteristic features of the sea ice cover. Breaking down of ice floes edge forms the ice ridges. Then, in accordance with a hypothesis of Parmeter and Coon (1972), their shape and height is a result of cinematic processes depended upon the thickness of the ice sheets making up the ice ridge. It is assumed that the ice ridge formation takes place on a line of contact between ice floes. The ice ridge formation is a dynamic process starting when shear or compression stress exceeds some critical value. The compression value required for the ice ridge formation can be expressed from the equations of conservation of mass and energy (Parmeter and Coon, 1972; Marchenko, 2001). Then the ice sheet starts to break-up unloading the ice cover and dissipating the accumulated energy.

Finally, the ice ridge is formed by the force balance between gravity and the carrying power acting on its keel part in the water. Hopkins et al. (1991) has used a numerical approach to model the sea ice ridge process in a two-dimensional case. Following him, from the equation for the hydrostatic balance, the volume of the ice ridge can be expressed by (Figure 5(b)):

$$
V=L t+\left(\rho_{i} / \rho_{w}\right)^{2}(t-h)^{2}(t-h)^{2} \cos (\varphi)
$$




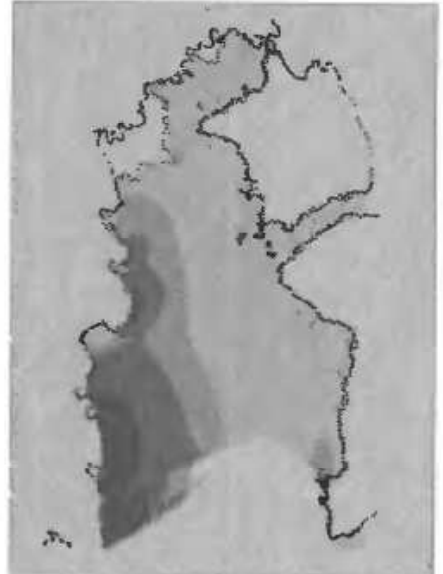

6-a: $(0-6) \times 10^{4} \mathrm{~N} / \mathrm{km}^{2}, t_{\max }=4.05 \mathrm{~m}$

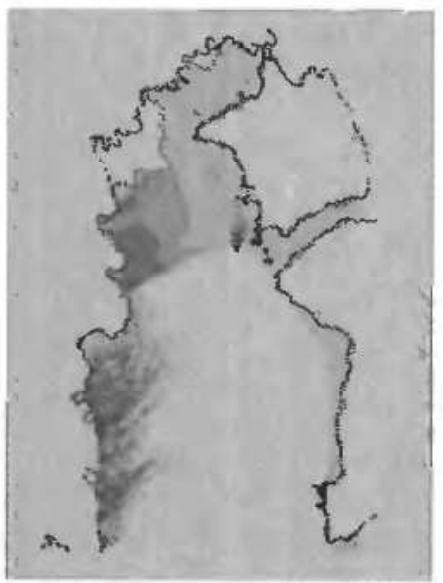

6-d: $(1.86-2.4) \times 10^{5} \mathrm{~N} / \mathrm{km}^{2}$, $t_{\max }=6.15 \mathrm{~m}$

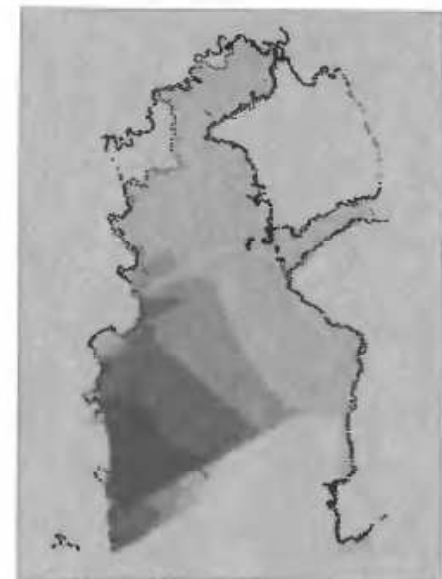

6-b: $(6-8.2) \times 10^{4} \mathrm{~N} / \mathrm{km}^{2}, t_{\operatorname{mex}}=6.53 \mathrm{~m}$

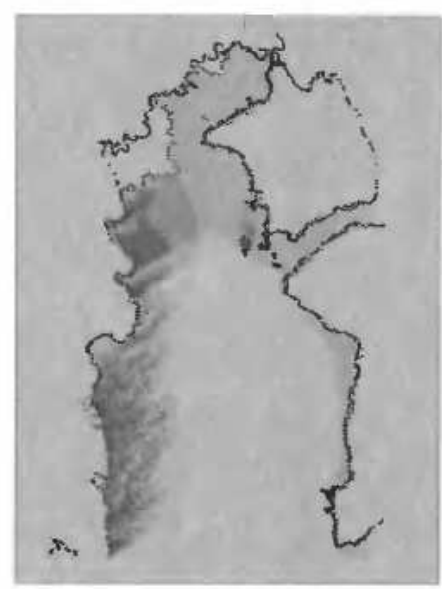

6-e: $(2.4-2.8) \times 10^{5} \mathrm{~N} / \mathrm{km}^{2}$, $t_{\max }=6.68 \mathrm{~m}$

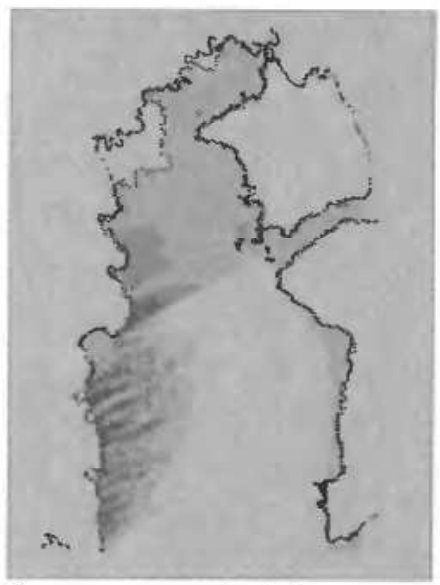

6-c: $(8.2-18.6) \times 10^{4} \mathrm{~N} / \mathrm{km}^{2}$,

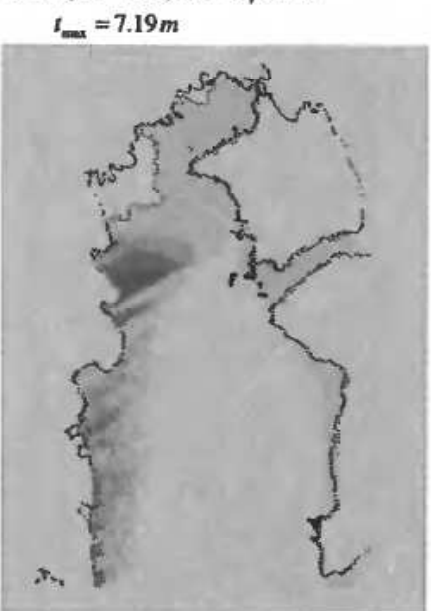

6-f: $(2.8-3.48) \times 10^{3} \mathrm{~N} / \mathrm{km}^{2}$, $t_{\max }=7.75 \mathrm{~m}$

Figure 6. The modeling of the ice ridging process in Storfjorden. The dashes indicate the ice ridges whereas the line width is proportional to their thickness $t$.

where $L$ is the length of the overlap area, $t$ is the ice ridge height, $h$ is the ice floe(s) thickness, $\rho_{i}$ and $\rho_{w}$ are the densities of the ice and water respectively. $\varphi$ represents the keel edge angle. From another side, the ice ridge volume can be obtained from the ice floes overlap magnitude (Figure 5(a)):

$$
V=(\alpha / \sin \alpha-1) \cos \alpha / 2 \cdot R h
$$

Finally, having joined equation (4.1) and (4.2), the current ice ridge thickness $t$ can be found as a positive root of the resulting quadratic equation. In every stage of the static equilibrium in the quasi-static simulation process (see section 3) the current ice ridge thickness was calculated and plotted as a solid redline in the area of the icefloes contact (overlap). Figure 6 shows the results of the ice ridge process simulation in Storfjorden. The parameters used in the experiment are as follows: 
Table 3. Initial parameters value for the modeling of ice ridge buildup process

\begin{tabular}{ll}
\hline Parameter & Value \\
\hline Floe radius: & $500 \mathrm{~m}$ \\
Floe thickness: & $1 \mathrm{~m}$ \\
$\#$ of disks in the system: & 7646 \\
$\rho_{i}:$ & $920.0 \mathrm{~kg} \cdot \mathrm{m}^{-3}$ \\
$\rho_{w}:$ & $1010.0 \mathrm{~kg} \cdot \mathrm{m}^{-3}$ \\
$\varphi:$ & $30^{\circ}(\mathrm{empirical} \mathrm{data})$ \\
Disk stiffness, $k_{n s}:$ & $5 \times 10^{9} \mathrm{~N} / \mathrm{m}$ \\
Normal/shear strength, $\sigma_{n s}:$ & $1 \times 10^{8} \mathrm{~N} / \mathrm{m}^{2}$ \\
\hline
\end{tabular}

In these experiments we assumed that the destruction of an ice floe edge is small and unload of compression stress caused by the ice ridge do not affect the system in common. The maximum values of the ice ridge thickness $t$ are shown beneath every sub-figure 6 coupled with the wind load range.

\section{Comparison with ERS-2 SAR images}

Figure 7(a) shows the opening of the Storfjorden polynya on 12 April 1998 observed by ERS-2 synthetic aperture radar, whereas the Figure 7(b) represents its manual segmentation into fast ice (white), pack ice (gray) and the polynya (black) including open water and drift ice.

The image shows leads along the typical break-off line "Agardh-FreemanDiskobukta" of the polynya and the size of the polynya is then dependent upon wind direction, wind speed and ice formation (Willmott et al., 1997).

In our study we used the average magnitude of wind speed for the model calibration. This disputable hypothesis is caused by the lack of in-situ data in Storfjorden. Nevertheless, it can determine the realistic model development. For instance, the Hopen meteorological database reveals the wind gust of $10.8 \mathrm{~ms}^{-1}$ in $4 / 12 / 98(4 / 12 / 98$ 19:00). By equation (2.1), it corresponds to the wind stress with magnitude of $2.1 \times 10^{5} \mathrm{~N} \cdot \mathrm{km}^{-2}$ and, hence, such stress can lead to the polynya state shown in Figure 4(d) that is in agreement with the satellite observations. The border between fast ice and polynya corresponds well to the ice edge from the equilibrium state under different loads, caused by stress of northeasterly winds. The stronger the wind stress, the bigger is the polynya area (Figure 4(e)-(f). The ice edge moves northward with increasing the wind stress magnitude.

The quantitative assessments of the ice ridge formation process show that the ice ridge keel height can reach the values of 7-8 $\mathrm{m}$ in Storfjorden. The bathymetry of the littoral zone along the eastern shore of Spitsbergen reveals the sea depths of about $40-60 \mathrm{~m}$. Thus, the ice ridges caused by the wind stress cannot become grounded ice, so called hummocks, by reaching the sea floor near eastern Spitsbergen.

\section{Summary}

This work presents the numerical approach to describe the Storfjorden polynya and its formation as well as the ice ridging processes due to measured wind stress during winter 1997/1998. We first represented and analyzed the ice cover as a plasticelastic two-dimensional media assuming sea-ice elasticity as a uniformly distributed stochastic function. Applying the dominant wind drag force (Figure 3) in 1997/98 we 


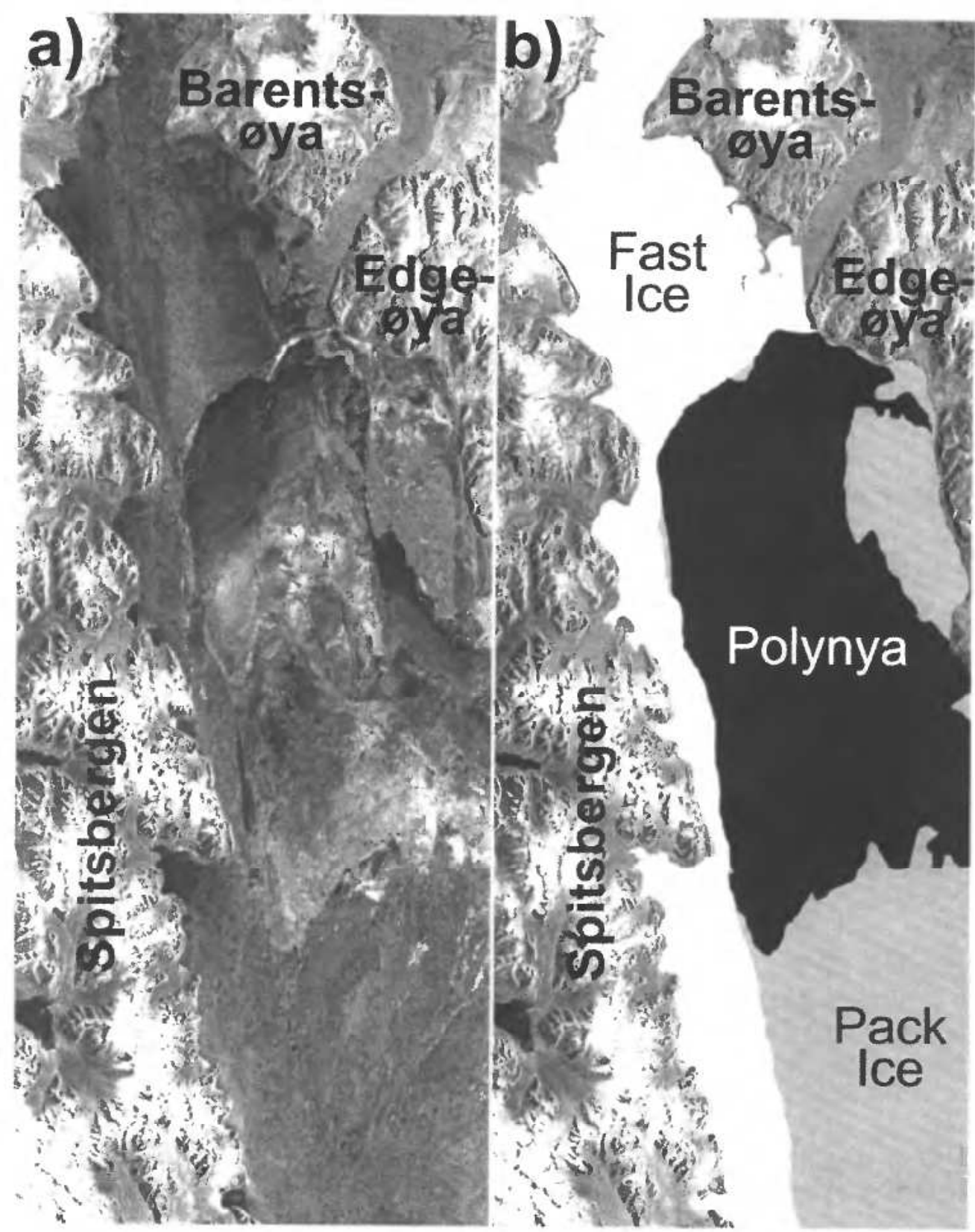

Figure 7. (a) The opening of Storfjorden polynya on 12 April 1998 observed by ERS-2 Synthetic aperture radar. (b) and its manual segmentation: fast ice is white, pack ice is gray and the polynya including open water and drift ice is black.

had the assessments of the maximum tensile stress and its distribution and used it later to calibrate the following quasi-static simulation.

Secondly, we fulfilled series of quasi-static simulations by means of pfc2d code and plotted the possible subsequent stages of the mechanical breakup of Storfjorden polynya.

The simulation database including the task sensitivity study (Zyryanov et al., 
unpub. mat.) has revealed that the Storfjorden shoreline and wind direction play a significant role in the polynya opening and development. As well as, in all simulation series Dolerittneset and Revneset seem to be responsible for the polynya opening, corresponding to the break-up position at the coastline.

Finally, the estimations obtained from hydrostatic balance show that the ice ridges in Storfjorden can reach $10 \mathrm{~m}$. of height along the eastern shore of Spitsbergen. The ice ridge formation is a complicate dynamic process most often investigated in the modern literature from the point of view of dissipating energy (Hopkins, 1999; Marchenko, 2001). This approach is used by authors in the further development of the model.

\section{Acknowledgements}

We wish to express our gratitude to A. Marchenko for his important comments and directions and to Harvey Goodwin (NP) for the map of Svalbard.

This work has been funded by grant N $128087 / 790$ from the Norwegian Research Council under contract with the Norwegian Polar Institute, Tromsø.

\section{References}

Banke, E. G., and Smith, S. D. (1973) Wind Stress on Arctic Sea Ice, J. Geophys. Res., 78(33), 7871-7883.

BJoRK, G. (1992) On the response of the equilibrium thickness distribution of sea ice to ice export, mechanical deformation, and thermal forcing with application to the arctic ocean, J. Geophys. Res., 97(C7), 11:287-11:298.

Crocker, G. B. and Wadhams, P. (1989) Breakup of Antarctic fast ice, Cold regions science and technology, 17, 61-76.

HAARPAINTNER, J. (1999) The Storfjorden polynya: ERS-2 SAR observations and overview, J. Polar Research, 18(2), 175-182.

HaARPaintner, J., Gascard, J.-C. and Haugan, P. M. (2001) Ice production and brine formation in Storfjorden, Svalbard, J. Geophys. Res., 106(C7), 14001-14013.

Hopkins, M., Hibler, W. D. III and FlAto, G. M. (1991) On the numerical simulation of the sea ice ridging process, J. Geophys. Res., 96(C3), 4809-4820.

Hopkins, M., TUHKURI, J. and LeNSU, M. (1999) Rafting and ridging of thin ice sheets, J. Geophys. Res., 104(C6), 13605-13613.

LANGLEBEN, M. P. (1972) A study of the roughness parameters of sea ice from wind profiles, J. Geophys. Res., 77(30), 5935-5944.

MarCHenko, A. V. (2001) Model for the formation of hummocks in a drifting ice cover, J. Physics-Uspekhi, 44(3), 315-320.

MeLLOR, M. (1983) Mechanical behavior of sea ice, CRREL Monograph, 83-1.

NaCAR, A., NeEDleman, A. and Ortiz, M. (1989) A finite element method for analyzing localization in rate dependent solids at finite strains, Computer methods in applied mechanics and engineering, 73, 235-258.

OVERLAND, J. E. (1985) Atmospheric boundary layer structure and drag coefficient over sea ice, J. Geophys. Res., 90(C5), 9029-9049.

OverLAND, J. E. and COLONY, R. L. (1994) Geostrophic drag coefficients for the central Arctic derived from Soviet drifting station data, Tellus, 46a, 75-85.

Parmeter, R. and Coon, M. D. (1972) A model of pressure ridge formation in sea ice, J. Geophys. Res., 77, 6565-75.

PeAsE, C. H. (1987) The size of wind-driven coastal polynyas, J. Geophys. Res., 92(C7), 7049-7059.

SChWARZ, J. and WeEKs, W. F. (1977) Engineering properties of sea ice, Journal of glaciology, 19(81).

THORNDIKE, A. (2000) Sea ice thickness as a stochastic process, J. Geophys. Res., 105(C1), $1311-1313$.

Willmot, A. J., Maqueda, M. A. M. and Darby, M. S. (1997) Model for the influence of wind and oceanic currents on the size of a steady-state latent heat coastal polynya, J. Phys. Oceunogr., 27(10), 2256-2275. 